\title{
DIAGNOSIS OF MYOCARDIAL DYSFUNCTION ACCORDING TO TISSUE DOPPLER DATA IN NEWBORNS WITH INTRAUTERINE GROWTH RETARDATION IN THE EARLY NEONATAL PERIOD
}

M.O.Gonchar, A.D.Boichenko, I.Yu.Kondratova, A.V.Senatorova Kharkiv National Medical University, Kharkiv, Ukraine

Actuality of the problem. Tissue Dopplerography (TD) provides greater depth for evaluation of the functionality of the attack at preclinical stage and is useful in diagnosing myocardial dysfunction and clinical decision-making on further tactics.

There is no universal method for diagnosis of diastolic dysfunction of the ventricles in newborns according to TD; therefore the interpretation of the results of the study should be based on the child's age and the functioning of the open arterial duct, as well as its hemodynamic significance.

Aim: Improvement of diagnosis of myocardial dysfunction of heart ventricles in newborns in the early neonatal period by tissue Dopplerography with definition of diastolic dysfunction type.

Methods: tissue Dopplerography.

The study involved examination of 64 full-term newborns with intrauterine growth retardation (IUGR), control group included 108 healthy newborns at gestation period of $39.1 \pm 0.8$ weeks without symptoms of myocardial dysfunction.

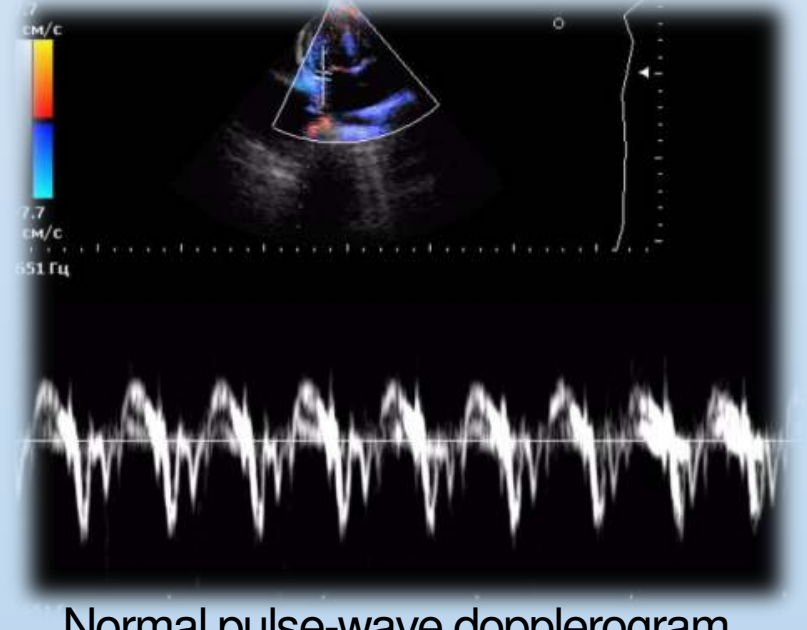

Normal pulse-wave dopplerogram of the lateral segment of the fibrous ring of the mitral valve

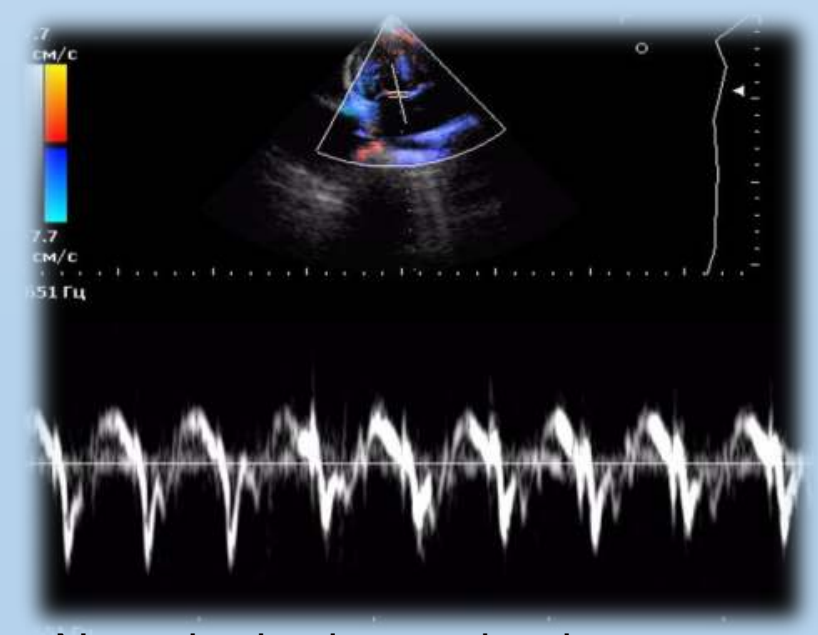

Normal pulsed-wave dopplerogram of the segment of the interventricular septum of the fibrous ring of the mitral

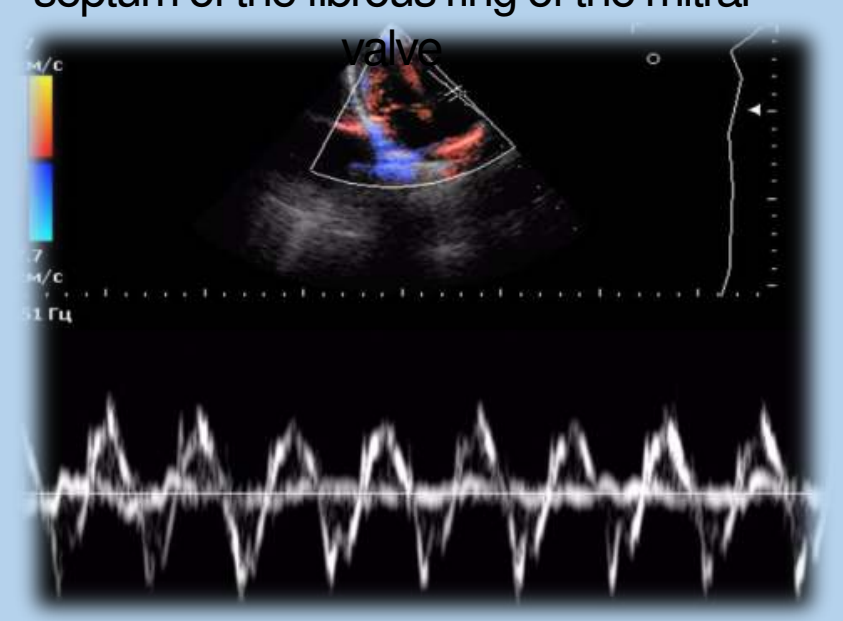

Normal pulse-wave dopplerogram of the lateral segment of the fibrous ring of the tricuspid valve
Results: Diastolic function by the type of delayed relaxation was observed in $28.1 \%$ newborns with IUGR. Violation of diastolic function by the type of delayed relaxation of the left ventricle (LV) was established in the maximum speed of early diastolic relaxation (E'max) (lateral section) $\geq 6.0 \mathrm{~cm} / \mathrm{s}$, the ratio of diastolic "peaks" of atrioventricular rings motion $\left(E^{\prime} / A^{\prime}\right)<1.0$, the ratio of the maximum speed of early transdermal blood flow to early diastolic relaxation rate $(E / E ') \leq 7.0$, the time of isovolumic relaxation (IVRT) $>62.3 \mathrm{~ms}$; right ventricle $(R V)-E^{\prime} \max$ (lateral section) $\geq 7.0 \mathrm{~cm} / \mathrm{s}, E^{\prime} / A^{\prime}<1.0, E / E^{\prime} \leq$ 8.0, IVRT > $61.1 \mathrm{msec}$;

Diastolic dysfunction of LV by the type of pseudonormalization was in $3.1 \%$ newborns with IUGR: $E^{\prime} \max <6.0 \mathrm{~cm} / \mathrm{s}, E^{\prime} / A^{\prime}<1.0, E / E^{\prime} 7.0-10.0$, IVRT > $62.3 \mathrm{~ms} ; \mathrm{RV}-\mathrm{E}^{\prime} \max <7.0 \mathrm{~cm} / \mathrm{s}, \mathrm{E}^{\prime} / \mathrm{A}^{\prime}<1.0$, E/E' 8.0-10, IVRT > $61.1 \mathrm{~ms}$.

Disturbance of diastolic function of LV by the restrictive type was not registered: disturbance of diastolic function of LV by the restrictive type $E^{\prime} \max$ (lateral section) $<4.4 \mathrm{~cm} / \mathrm{s}, E^{\prime} / A^{\prime}<1.0, E / E^{\prime} \geq 10.0$, IVRT $<47.0$ $\mathrm{ms} ; \mathrm{RV}-\mathrm{E}^{\prime} \max$ (lateral section) $<4.0 \mathrm{~cm} / \mathrm{s}, \mathrm{E}^{\prime} / \mathrm{A}^{\prime}<1.0, \mathrm{E} / \mathrm{E}^{\prime} \geq 10.0$, IVRT $<49.0$ ms.

Uncertain type of LV diastolic dysfunction was diagnosed in $3.1 \%$ newborns with IUGR: uncertain type of LV diastolic dysfunction - E'max (lateral section) $\geq 6.0 \mathrm{~cm} / \mathrm{s} ; \mathrm{RV}$ - E'max (lateral department) $\geq 7,0$ and in the presence of different schedules of complexes in different heart cycles.

Conclusions: We consider that interpretation of findings should be done taking into account the day of the child's life and functioning of patent ductus arteriosus, its hemodynamic significance, as confirmed by the dependence between the diameter of patent ductus arteriosus and speed of early diastolic relaxation of LV septal department $(r=-0.38, p=0.003)$.

Sources: Otto Catherine M. Practice of Clinical Echocardiography E-Book // Edition 5. Philadelphia, Pennsylvania: Elsevier, 2016. 990 p. Guidelines for the echocardiographic assessment of the right heart in adults: a report from the American Society of Echocardiography endorsed by the European Association of Echocardiography, a registered branch of the European Society of Cardiology, and the Canadian Society of Echocardiography / LG. Rudski, WW. Lai, J. Afilalo [et al.] // J Am Soc Echocardiogr: 2010. 23 (7). P. 685-713; Cardiac dysfunction is associated with altered sarcomere ultrastructure in intrauterine growth restriction. / J. I. Iruretagoyena, A. Gonzalez-Tendero, P. Garcia-Canadilla [et al.] // Am J Obstet Gynecol. 2014. Vol. 210, № 550. e1-7. 